\title{
Informal institutions and radical ideologies under institutional transformation
}

\author{
Irina Starodubrovskaya \\ Gaidar Institute for Economic Policy
}

\begin{abstract}
This article questions one of the central postulates of institutional economic theory, i.e., that of the sustainability and purely evolutionary changes of informal institutions. To study the phenomenon of the destruction of informal institutions and its consequences, we use the tools of sociological theory, which acknowledge that a period of intensive urbanization is characterized by anomie, i.e., a lack of norms, in which traditional institutions are destroyed, while new urban institutions have not yet taken shape. We reviewed the possible reactions of communities and individuals to the conditions of anomie, including the compensatory mechanisms of ideologies. In the case of the Dagestan Republic, we show how the proliferation of fundamentalist Islamic ideology is associated with the state of anomie and the consequences to which it could lead from an institutional point of view. The analysis of the situation in Dagestan is based on long-term field research conducted in the region. (C) 2015 Non-profit partnership "Voprosy Ekonomiki". Hosting by Elsevier B.V. All rights reserved.
\end{abstract}

JEL classification: $\mathrm{B} 52, \mathrm{Z12}, \mathrm{Z13}$.

Keywords: institutional change, informal institutions, anomie, intergenerational conflict, Islamic fundamentalism.

\section{Introduction. The sustainability of informal institutions: Axiom or myth?}

The theory of institutional change, as a part of institutional economic theory, hinges on the postulate of the impossibility of abrupt restructuring of informal

\footnotetext{
* The updated English version of the article published in Russian in Economic Policy, 2015, Vol. 10, No. 3, pp. 68-88. the article was prepared based on a 2014 study entitled "Social Roots of Terrorism in the North Caucasus," conducted by the Gaidar Institute for Economic Policy. The objective of the study was to identify the sources of demand for radical ideologies and terrorist methods of achieving goals in the institutional conditions of the North Caucasus.

E-mail address: irinas@iet.ru.

Peer review under responsibility of Voprosy Ekonomiki.
} 
institutions and on the related effect of "path dependence". The logic of these relations is studied in the greatest detail in the works of Douglas North, which we use as an example in our review below.

According to North, a society's institutional structure shapes the game rules, incentives and restrictions that govern relationships between individuals and thus reduces the uncertainty inherent in those relations: "All organized activity by humans entails a structure to define the 'way the game is played'... That structure is made up of institutions - formal rules, informal norms, and their enforcement characteristics" (North, 2005, p. 48).

Formal, written rules are established and changed primarily by the state and are "created to serve the interests of those with the bargaining power to devise new rules" (North, 1990, p. 16). Informal rules derive from the culture, which "consists of the intergenerational transfer of norms, values, and ideas" (North, 2005, p. 50).

Interaction between formal and informal rules is quite a complex process. On the one hand, informal constraints are "extensions, elaborations, and modifications of formal rules" (North, 1990, p. 40). On the other hand, "the informal constraints that are culturally derived will not change immediately in reaction to changes in the formal rules. As a result the tension between altered formal rules and the persisting informal constraints produces outcomes that have important implications for the way economies change" (North, 1990, p. 45).

Influential political and economic organizations can invest resources to maximize the target function within the framework of existing institutional restrictions or to attempt to change them. "Maximizing behavior by the firm can take the form of making choices within the existing set of constraints or of altering the constraints... Which direction the firm or economic organization takes depends upon its subjective perception of the payoffs" (North, 1990, p. 79). The same algorithm, in fact, applies to politics. Under such conditions, "the immediate instruments of institutional change are political or economic entrepreneurs who attempt to maximize at those margins that appear to offer the most profitable (short-run) alternatives" (North, 1990, p. 100).

Incentives for investing in change emerge in the event of an institutional imbalance, i.e., in a situation contrary to those when "given the bargaining strength of the players and the set of contractual bargains that made up total economic exchange, none of the players would find it advantageous to devote resources into restructuring the agreements" (North, 1990, p. 86). An institutional imbalance can have various causes. "New or altered opportunities may be a result of exogenous changes in the external environment which alter relative prices to organizations; or they may be a consequence of endogenous competition among the organizations of the polity and the economy that induce the growth of knowledge and hence innovations" (North, 2005, p. 60).

However, even when these changes are formally radical in nature (conquests, revolutions), they are essentially incapable of completely detaching from the past. "Although a wholesale change in the formal rules may take place, at the same time there will be many informal constraints that have great survival tenacity because they still resolve basic exchange problems among the participants, be they social, political, or economic. The result over time tends to be a restructuring of the overall constraints - in both directions - to produce a new equilibrium that is far less revolutionary" (North, 1990, p. 91). 
In light of the above considerations, North regarded the process of institutional change as evolutionary in nature: "The dominant beliefs - those of political and economic entrepreneurs in a position to make policies - over time result in the accretion of an elaborate structure of institutions that determine economic and political performance. The resultant institutional matrix imposes severe constraints on the choice set of entrepreneurs when they seek to innovate or modify institutions to improve their economic or political positions. The path dependence that results typically makes change incremental" (North, 2005, p. 2). ${ }^{1}$

At the same time, in many of his papers North has emphasized two factors contradicting his otherwise coherent theory of institutional change.

First, North has admitted that history has seen exceptions to his model, when informal restrictions did not create insurmountable obstacles to institutional change, while "the occasional radical and abrupt institutional change suggests that something akin to the punctuated equilibrium change in evolutionary biology can occur in economic change as well" (North, 2005, pp. 2-3). Moreover, North himself, with a team of co-authors in the book "Violence and Social Orders. A Conceptual Framework for Interpreting the Written History of Humankind" (North et al., 2009), considered this very case of radical institutional transformation in a number of countries, i.e., the transition from a limited access order to an open access order. However, in this book, the process of transforming informal institutions is not studied thoroughly, although such an analysis might shed light on the mechanisms of institutional change.

Second, North's stumbling block was the role of intangible incentives in shaping and changing informal institutions, in which an individual "gives up wealth or income for some other value in his or her utility function" (North, 1990, p. 40). "The importance of self-imposed codes of behavior in constraining maximizing behavior in many contexts also is evident. Our understanding of the source of such behavior is deficient" (North, 1990, p. 43).

To understand where to look for answers to these questions (closely related, as shown below), one should remember that the problem of institutional change has not been analyzed by institutional economic theory alone. The first prominent sociological papers were dedicated to the transformation of society from the traditional and agricultural model to a modern and urban one. It was noted then that this process was not evolutionary in nature: between the destruction of old social controls and the emergence of new ones, a type of "gap" occurs, i.e., a period during which the former controls no longer work, while the latter have not yet

\footnotetext{
1 This example of North's views is provided for the sake of convenience, because it is important to reveal the internal logic of a specific theoretical approach, rather than to provide a detailed review of the literature. However, such views are apparently very common both beyond and within institutional economic theory. Regarding political institutions, this fact was emphasized by Helmke and Levitsky. They acknowledged the possibility of rapid transformations of informal, spontaneous institutions according to the "tipping" model. However, they interpreted the matter quite abstractly: "One means of explaining such rapid transformations are tipping models of cultural change. These models suggest that, if a sufficiently large number of actors become convinced that a new and better alternative exists, and if a mechanism exists through which to coordinate actors' expectations, a shift from one set of norms to another may in fact occur quite rapidly" (Helmke and Levitsky, 2003 , p. 23). It remains unclear why, at some point, a large number of actors start to believe in a new and better alternative, from where the coordination mechanism comes and, finally, why "path dependence" ceases to have an effect whenever any sufficiently vital institutions are concerned. In this case, this type of possibility has been discussed, but no exhaustive explanation for it has been provided.
} 
been formed. "The scale is upset; but a new scale cannot be immediately improvised. Time is required for the public conscience to reclassify men and things. So long as the social forces thus freed have not regained equilibrium, their respective values are unknown and so all regulation is lacking for a time. The limits are unknown between the possible and the impossible, what is just and what is unjust, legitimate claims and hopes and those which are immoderate. Consequently, there is no restraint upon aspirations" (Durkheim, 2005, p. 213).

This phenomenon, related to the destruction of informal controls in the situation of the intensive migration of the rural population to cities, was called anomy by Durkheim, translated as the absence of norms. ${ }^{2}$ According to the social theorists of the late 19th and early 20th centuries, people who find themselves in situations of anomy feel lonely and lost, without any bearings. "Anomy... by allowing requirements to exceed appropriate limits, throws open the door to disillusionment and consequently to disappointment. A man abruptly cast down below his accustomed status cannot avoid exasperation at feeling a situation escape him of which he thought himself master" (Durkheim, 2005, p. 248). This person's perception of life is characterized by disappointment and devaluation of the objective world, "dragging the personality downward into a feeling of its own valuelessness" (Simmel, 2002, p. 15). "Personal disorganization, mental breakdown, suicide, delinquency, crime, corruption, and disorder might be expected under these circumstances to be more prevalent in the urban than in the rural community" (Wirth, 1938, p. 23).

\section{Compensatory mechanisms against anomie}

Later, the social sciences questioned the concept of anomie. Studies of urbanization in various countries proved that traditional links are not always so abruptly torn, nor are traditional social systems instantly destroyed, as could be concluded from the works of some earlier social theorists. ${ }^{3}$ Thus, for example,

\footnotetext{
${ }^{2}$ North's works contain a notion similar to that of "anomie," i.e., "disorder" as the antithesis of "order" (see e.g. North, 2005, ch. VIII). "Disorder increases uncertainty because rights and privileges of individuals and organizations are up for grabs, implying disruption of existing exchange relationships in both political and economic markets; and conformity disappears as a result of disintegration of norms and/or change in enforcement" (North, 2005, pp. 105-106). However, North linked disorder first of all to political processes (e.g., revolutions) and explained it through the actions of political entrepreneurs, completely ignoring the problem of sustaining informal norms in this context.

3 And far from all of them, by the way. In this context, the works by Robert Park appear quite underestimated. For him, a city is a dialectical unity of segregation and "melting pot" processes. "Upon careful consideration, an urban community appears to be a mosaic of smaller communities, many of which differ drastically from each other, but all of which are more or less typical. Every city has its central business district, the concentration point of the entire business complex. Any city, especially a large one, has its own more or less self-contained residential neighborhoods and suburbs, areas of light and heavy industry, satellite towns, and a temporary labor market where men are hired for unskilled labor... Every American city has its own slums, ghettos and immigrant colonies, i.e., neighborhoods that preserve a more or less alien and exotic culture. Almost every major city has its bohemian and slum districts, where life has more freedom, adventure and loneliness than in other places" (Park, 2011 b, p. 100). Each of these habitats is characterized by its own specific culture: "...each natural habitat is, or tends to become, a cultural habitat over the natural course of events. Each natural habitat has, or tends to have, its own specific cultural traditions, customs, conventions, standards of decency and decorum, and if not its own special language, then at least a general universe of discourse, in which words and deeds have their meanings, distinctly characteristic of each local community" (Park, 2011b, p. 105). At the same time, the city functions as a melting pot in a way that a person in it is not permanently tied to his or her neighbors and is not included
} 
D. Brower, who studied urbanization in Russia, argued that Russian peasants who migrated to cities did not experience anomie because their entrance into the urban culture was facilitated by geographic and professional communities (Brower, 1990, p. 89). Experts on African cities have argued that such cities are not "melting pots" because the Africans who move there preserve their tribal identities and membership in rural communities (Shack, 1973, p. 251). However, are these examples sufficient grounds for thinking that researchers have misdiagnosed societies with intensive urbanization? Here, some serious doubts arise.

First, the phenomenon of anomie, studied by social theorists during the late 19 th and early 20th centuries, and the type of personality formed under its influence apparently existed in reality. History has provided proof of this existence. For example, wordings almost completely matching the characteristics reported by Simmel and Wirth appear in the movement of personalists who emerged in a number of European countries in the 1930s and who advocated the ideas of federalism (Burgess, 2006, p. 173). However, the most eloquent descriptions of anomie are not found in the scientific literature but rather in fiction. Andrey Bely's novel Petersburg describes this situation with surprising clarity. Characters, meanings and even things are indefinite, variable, and volatile.

"I get confused in every phrase. I try to say a word, but instead I say something completely different: I keep missing the point... Or I may forget what to call an absolutely ordinary object, and when I remember it, I doubt if it really is that thing" (Bely, 2011, p. 240).

There is nothing stable or clear and no bearings. A mist is all around. There is no use for centuries-old traditions. As in Apollon Apollonovich's dream,

"Suddenly, the senator exclaimed for the second time:

- Based on which rule?

- And which paragraph?

And the emptiness replied:

- There are no longer any paragraphs or rules! (Bely, 2011, p. 286).

Further, the very characters, disharmonious and "slightly rotten," with no goals or objectives in life, look hopelessly sick:

"And you think I'm the only one who's sick? No way: you, Nikolay Apollonovich, you are also sick. Almost everyone is sick" (Bely, 2011, p. 247).

Second, during the late 19th and early 20th centuries, social theorists might have actually simplified the situation, arguing that the phenomenon of anomie, caused by the destruction of the old informal institutions in a society, is directly

(continued) in a single cultural environment for a lifetime. Thus, spatial mobility can be a reflection of vertical mobility. Moreover, a resident can exist simultaneously in different cultural habitats with different systems of traditions and values. "Segregation processes establish moral distances that turn the city into a mosaic of tiny worlds, tangential but not penetrating each other. This enables individuals to quickly and easily move from one moral milieu [environment] to another and encourages the fascinating but dangerous experiment of living in several different worlds at once, possibly bordering on each other but divided by a wide gap” (Park, 2011a, p. 51). 
related to the isolation, loneliness and disappointment of an individual who "becomes a problem for society, as well as for himself" (Park, 2011b, p. 109). Anomie shapes the challenges to which different communities and individuals might react differently.

The examples of a Russian artel' and the loyalty of ethnic communities to their tribal identities in Ethiopia are also reaction to anomies related to the tendency to preserve the old principles of social controls in a self-contained group. In Ethiopia, this tendency was manifested in a situation in which people migrating from rural areas to the city actually found themselves in a dual system of social control, i.e., tribal traditions and norms on the one hand and a legal system on the other (Shack, 1973, p. 273). The situation was essentially different in Russia. While the norms and rituals of interaction between rural migrants originated partly from rural life, they were clearly marked by anomie and caused regular and excessive consumption of alcohol, demonstrations of manhood through fistfights, and occasional sex with prostitutes (Brower, 1990). These norms, in turn, led to the disintegration of traditional rural customs and the informal institutions inherent in it. Under the influence of a specific migrant culture, in rural areas, "informal social controls were used to relax, especially in areas dominated by seasonal work, where public opinion became lax, even about abortions, adultery and prostitution" (Mironov, 2000, p. 467).

However, the preservation of a certain form of group self-containment and intergroup regulation could not have been the universal choice of rural migrants because it signified the abandonment of two fundamentally important advantages of urban life, i.e., education and vertical mobility within an urban society. Thus, this environment had to devise other reactions to anomie.

One of these reactions is quite apparent and is associated with the selfish exploitation of anomie. If anomie is a lack of norms, then it must be characterized by the "rule of force". This aspect is associated with the inevitable proliferation of a criminal culture under anomie. The norms of that culture also enable structuring relationships with one's neighbors (or, in any case, with a majority of them). The criminal culture appears to be far more universal than the types of norms considered above. Interpersonal relationships within it are not necessarily bounded by traditional ties (family, tribal, geographical), and they pose far fewer barriers for a migrant to integrate into the urban environment. ${ }^{4}$

Do the above examples exhaust the models of how people react to anomie? Ulrich Matz, who considers ideologies to be compensatory mechanisms against anomie, offered an exceptionally interesting answer to this question. In his opinion, it is more productive from a heuristic point of view to "apply the concept of ideology to a system of beliefs of a type that is naturally brought to the forefront during serious social crises. From this point of view, ideologies are systems of values that, while acting as a political world view and having the power of faith, possess an especially high orientation potential and are thus able to rein in the processes of social anomie resulting from the crisis" (Matz, 1992, p. 131). ${ }^{5}$

\footnotetext{
${ }^{4}$ It should be noted that the proliferation of criminal culture was also a reaction in various (mainly urban) communities to the post-Soviet anomie, caused by the destruction of the old economic, social and ideological system and the abrupt change in living conditions.

5 At the same time, it should be considered that Matz viewed anomie in a broad sense, as a general characteristic of modern culture associated with the diminishing role of tradition and values of freedom.
} 
Thus, we can form a hypothesis answering both questions that were not answered by North's theory of institutional change. Informal institutions do not always change in an evolutionary manner. Significant societal shifts, such as mass urbanization, can trigger intensive dilution of informal institutions, leading to anomie, i.e., an absence of social controls, in which old rules and norms have been destroyed, and new ones have not yet taken shape. An exit from the "path" is possible under these conditions. Ideologies are among the possible reactions by individuals and communities to anomie, enabling them to position themselves in a society and to structure their interactions with others to a certain extent. Because, under anomie, the need to reduce uncertainty in relationships between people is vital, it comes as no surprise that "ideas, organized ideologies, and even religious zealotry play major roles in shaping societies and economies" (North, 1990, p. 44).

At the same time, anomie provides a key to understanding another phenomenon related to the dilution of informal institutions. As noted above, informal rules are directly related to the intergenerational transfer of norms, values and ideas. From the point of view of the institutional theory, the benefits of this transfer are obvious. Using the term "artifactual structure," i.e., the institutions, tools and technologies determined by cultural legacy, North argues that "the richer the artifactual structure, the greater the reduction of uncertainty in making choices at a moment of time... The richer the artifactual structure, the wider the range of routine decisions that can be made. In effect, the game has been structured to relieve the individual of uncertainty in choice making" (North, 2005, p. 36).

However, with an abrupt change in the external environment of individuals' activities, i.e., in the nature of the society in which their activities occur (a change from a rural community to an urban setting), the economic basis for their existence (transition from agricultural to other activities), the norms deriving from the culture are mostly devalued because they no longer serve as tools to reduce uncertainty for individuals. The recipes that worked to organize life for previous generations are no longer able to assist the contemporary generation. Moreover, they might even hinder adaptation to new conditions. "The reproduction of cultural tradition is supported by social practices that discourage or limit experimentation with alternatives, and inhibit searches for other ways of seeing things" (Calhoun, 1997, p. 131). Such a situation is ripe for not only the emergence but also an open manifestation of intergenerational conflict. Without the opportunity or will to use the life recipes of the older generation, the young begin to look for their own values and meaning which differ from those shared by their ancestors.

The conflict of parents and children is a theme described in Russian philosophy and literature during the period of profound social transformation that followed the abolition of serfdom. In this context, we can recall — in addition to Ivan Turgenev's famous novel Fathers and Sons - Andrey Bely's novel, in which revolutionaries propose that the son of a prominent government official plant a bomb to kill his father, although he is hesitant to accept this suggestion. Intergenerational relationships are also considered in the famous collection Vekhi ("Milestones"), in which, in particular, it is noted that only the traditional families of Slavophile nobility succeeded in preserving the continuity of generations, "while progressive families lacked this principle, and the children of our most talented novelists, satirists and political writers began to turn away from 
their fathers" (Izgoyev, 2011, p. 264). Thus, they receive their upbringing and system of values "in their new environment of comradeship," and "comradeship is the only cultural influence that our children are subject to" (Izgoyev, 2011, p. 268). Spiritual pedocracy, i.e., the spiritual government of the children, provokes great indignation among the conservative authors of the collection: "the discipline of obedience should assist in the development of patience in the face of history, self-mastery, and stability of life; it teaches us how to endure the burdens of history, the yoke of obedience in history; it creates a certain 'earthiness', a sense of connectedness with the past and grateful indebtedness to it - something that is now so easily forgotten for the sake of the future. It restores the moral bond between children and parents. Humanistic progress, in contrast, means contempt for one's forbears, a turning away from one's past and a wholesale condemnation of it, and ingratitude that is both historical and frequently, simply personal, a legal act of spiritual separation between fathers and sons" (Bulgakov, 2011, pp. 82-83).

In social theory, the intergenerational conflict is also present as a factor in institutional transformation, although apparently insufficient attention has been paid to it. "During their formative years, people do not necessarily absorb all of the values that their societies attempt to instill in them. Individuals are most likely to adopt those values that are consistent with their own firsthand experience. This makes it possible for intergenerational value change to take place. If younger generations are socialized under significantly different conditions from those that shaped earlier generations, the values of the entire society will gradually change through intergenerational replacement" (Inglehart and Welzel, 2011, p. 99). ${ }^{6}$ It is of paramount importance that the study of values confirmed the sustainable existence of the intergenerational value gap, independent from a person's "life cycle": over time, the advocates of new values do not change their value orientations and do not begin to support traditional values.

Thus, the ideologies used by the younger generation to compensate for anomie are characterized by yet another trait, i.e., they must differ from the ideologies of previous generations and must create room for an independent understanding of the world and a person's role in it.

\section{The ideology of Islamic fundamentalism as a reaction to anomie- the case of Dagestan}

In the previous sections, we analyzed the theoretical approaches to the problem of the sustainability of informal institutions during institutional transformation and reactions by individuals and communities to their dilution (anomie). We have found out that one of the most important compensatory mechanisms against anomie is ideology, which, under the conditions of an intergenerational conflict, inevitably breaks ties with the cultural and normative traditions of past generations. Below we consider a particular example of the effects of these

\footnotetext{
${ }^{6}$ At the same time, the authors consider this value gap to be manifested to the greatest extent in post-industrial democracies and Western post-communist countries. It appears that a study conducted as part of the World Value Survey succeeded in capturing the intergenerational conflict under conditions of a post-modern transition, but it proved unable to reflect it for a modern transformation.
} 
mechanisms, i.e., the proliferation of the ideology of Islamic fundamentalism in the Republic of Dagestan 7 from the late 1980s to the early 1990s. The Republic of Dagestan is not an arbitrary choice. It is there that the destruction of institutions and the ensuing anomie have been most noticeably manifested as a result of the simultaneous effect of three groups of factors.

First, the entire country was struggling through a very severe economic, political and ideological crisis that was caused by the fall of the communist regime and the collapse of the Soviet Union. The resulting anomie was manifested across Russia, although to varying extents.

Second, the general situation in Russia coincided with mass migration in Dagestan. In most cases, migration involved rural populations moving from the mountains to the valleys and from rural areas to cities and, at the same time, the mass exodus of Russians and educated locals - primarily the urban population - from Dagestan. Although these processes were characteristic of the Soviet era (the latter more characteristic of the late-Soviet era), it was during the period in question that they became so intensive.

This intensity resulted in the dilution of the traditional norms that had been preserved in rural areas and that the Soviet government, with its conservative modernization, had changed only slightly or perfunctorily. This dilution was supported by globalization processes, including specifically Islamic globalization, which was associated with the mass travel by youths to centers of Islamic thought to receive educations, as well as with the penetration of market relations into rural communities. At the same time, the mass exodus of the urban population from the republic destroyed the rudimentary urban culture that had developed by that time. Dagestan began to turn into a "quicksand society," where the country sucked up the city (an expression attributed by K. Schlögel (2012, p. 296) to Moshe Lewin).

The transformation of the region's capital city is highly illustrative of the process. Experts identified two stages of demographic change in Makhachkala. The first occurred in the 1990s (1989-2000) and was characterized by the replacement of the Soviet-era urban population with "new urbanites". The population was almost constant at approximately 300,000 during that period, maintaining the late Soviet level. However, only one-third of the Soviet-era population remained, while the remainder were migrants who replaced them. Starting roughly from the 2000 s, the city began to grow in size, caused not only by the ad-

\footnotetext{
7 The Republic of Dagestan is the North Caucasus's largest republic in terms of area and population and Russia's southernmost constituent republic. Densely populated, it accounts for $0.3 \%$ and $2.0 \%$ of Russia's area and population, respectively. The population is close to 3 million. The birthrate is substantially higher than the Russian average, although it has been declining and nearing the mere reproduction level. The proportion of the urban population is quite stable according to statistics and is significantly less that the Russian average. However, urbanization is in fact progressing quite rapidly there.

Dagestan is an underdeveloped Russian region: its per capita gross regional product is 2.6 times less than the Russian average (2013), while the average wage is 1.7 times less (2014). The official unemployment figure is twice as high as the Russian average. However, economic statistics for the region are unreliable, because there are significant shadow economy activity and employment. This factor partially accounts for estimates of the population's cash income, which were only approximately 17 percent less than the Russian average in 2013. Dagestan has recently demonstrated rapid growth in the official economy. It is a republic that is heavily dependent on federal subsidies, which account for $70 \%$ of its budget. At the same time, per capita revenues of the regional consolidated budget are nearly half of the Russian average.
} 
ministrative annexation of adjacent territories but also by the active migration of the rural population into the city suburbs. Today, Makhachkala's population is approximately 700,000, while the Makhachkala metropolitan area has more than a million people (Starodubrovskaya et al., 2012, pp. 257-258).

Third, the wars in neighboring Chechnya also had a noticeable impact. Except for a short period in 1999, Dagestan's population did not suffer any hardships directly related to the hostilities. However, these processes severely affected the socialization of young people in many areas, especially those bordering on Chechnya. Some of these people temporarily left the traditional rural hierarchies and underwent training in Chechen terrorist camps, and some participated in the fighting. Moreover, the Chechen wars greatly aggravated the economic crisis in Dagestan, accelerating the collapse of the previous economic relations.

Thus, the situation of anomie and intergenerational conflict in Dagestan was deeply rooted and affected large territories, rural as well as urban, which is why studying the reactions of particular individuals and communities to the destruction of informal norms and the role of Islamic fundamentalism in this process in this particular region might produce the most definitive results. The vast majority of information below was obtained through field research in Dagestan.

Anomie primarily creates demand for reducing uncertainty: both institutional and that related to values. As noted above, under conditions of anomie, people lose their bearings, their clear perception of good and evil and right and wrong, and what they should live for. In such a situation, Islam's significant advantage is that it regulates almost all areas of life for its believers in greater detail than any other global religion.

"Islam is not only a religion; it's a way of life that provides answers to every situation for a person. It's the only religion that regulates everything, from going to the toilet and washing oneself to all of the principles. You will find all the answers there". 8

Islam forms the very framework of life for its believers, replacing the destroyed institutional framework of the society.

\footnotetext{
${ }^{8}$ The italicized texts are quotes from interviews with informants, mostly representatives of Islamic fundamentalism, during the research conducted from 2012 to 2014. The research used qualitative methods. Approximately 70 individual and group interviews were conducted with advocates of Islamic fundamentalism. An overwhelming majority were men aged between 25 and 40 years old. Several interviews were conducted with "patriarchs" of the movement, who were more than 50 years old. Thirty-seven interviews were conducted with urban citizens and the remainder with rural citizens (10 villages). An overwhelming majority of interviews were conducted in Dagestan, but the research also covered Kabardino-Balkaria and Karachay-Cherkessia. This article is based on materials from Dagestan, although in some cases Muslims from Karachay-Cherkessia are quoted when they more clearly expressed the thoughts that were also voiced in Dagestan.

Informants were attributed to categories according to the following criteria:

- self-identity (identification with one of the three conventionally fundamentalist movements represented in the North Caucasus: Salafis, Ikhwan, and Hizb ut-Tahrir); and

- visiting a mosque perceived in the public and personal consciousness as Salafi (provided that such a mosque was within the geographical scope). For example, in Makhachkala, this criterion included the mosques on Kotrova Street and on Vengerskikh Boitsov Street and a few mosques in the suburbs.

In general, urban informants could be classified as Islamic intellectuals (journalists, social and political activists, lawyers, imams) and Islamic businessmen. In rural areas, the informants belonged to various social strata. The sampling used the snowball methodology.
} 
"When your life becomes filled with numerous clear distinctions, and each idea has been to the maximum extent... articulated for you, i.e., you understand what this or that actually is, the goals in your life... are most solid and clear, and you know how to achieve them... your life becomes much simpler".

Moreover, amid the exceptional volatility and unpredictability of modern life, Islam provides certainty that a Muslim who abides by all of the commandments of the religion will necessarily go to heaven (which constitutes a sort of contract with God, secured while there are no mechanisms to secure any other type of contract), and this belief provides the person with a sense of a definite future, which they fail to find in this world. "When everything else is volatile, and threats to life, health and well-being are extremely high, let this one contract with God be secured and give me stability" was a thought voiced more than once by interviewees in the North Caucasus.

At the same time, one should realize that demand for goal-setting and moral positioning in life is, to a considerable extent, an urban demand. It is not satisfied by the notion that everything is good that is customary (as in traditional regulatory systems) or beneficial (as in the criminal world, for example).

"I was able to find myself in this system [i.e., in Islam]; there are no problems. I'm honest with the society, with my family, and with my children, and I have no need to swindle or cheat to gain material benefit".

The emergence of this demand is, possibly, one of the main reasons why great numbers of young people in almost all Muslim regions left the criminal environment for Islam at a certain point. At the same time, this demand was formed by those who were not sufficiently urban to allow them not to rely on their own opinions and on their own perceptions of good and evil, which is why the question of whether everything condoned by religion is morally justified or whether everything condemned by religion is immoral is simply not asked in this system of values. The equals sign is put there automatically. Finding truth and justice here would be equal to finding the right decision in accordance with religious norms.

However, Islamic fundamentalism appears to satisfy more than only the desire to find bearings in life. The absence of generally accepted norms, the ineffectiveness of written and unwritten rules, the possibility of gaining undeserved illegitimate benefits outside the legal framework - all of these factors create demand for a new normativity and encourage the search for its sources. At the same time, this demand is two-sided.

On the one hand, it is the demand for new mechanisms to control the behavior of individuals under conditions in which traditional mechanisms of external control (within which the community directly regulates the lives and behavior of each of its members) no longer work, while new ones have not yet taken shape. On the other hand, some continue hope to restore the old models of control, i.e., the traditional, Soviet models.

"We need to restore order... To control every person, to control what they do at work... Say, why does a man have a palace like that when his monthly wage from the state is 20,000 rubles?. Where did he get the money? In old times, 
the communists used to take it seriously. They audited his wages; for example, can he buy this or afford that? No? Then they would take it all away from him. What do we have now? Nobody controls it".

However, there are quite a number of young people, mainly urbanites, who clearly understand that a return to these procedures of external control is now impossible. How does one protect oneself and one's children from temptation in this situation? The formation of internal moral controls ${ }^{9}$ associated with the development of an urban environment, as mentioned above, is in its infancy. While not denied completely, it does not invoke trust either.

"There are people... who are not tainted, who don't steal. But they are very few".

Consequently, there is a need for an ersatz external controller that would not require the physical presence of a controlling elder but, at the same time, would create a sufficiently strong fear of punishment for a person to stay within the limits. Religion is exactly what enables this form of control, which is, in essence, a transition from external control to internal one.

"As soon as your child begins to grow up, your control is reduced, and nothing will hold him... You can't protect him in any way... He stops listening to his mother, his father, or anyone else and only listens to the environment in which he lives. Whereas when you give him self-control in the form of religion, which explains certain things to him, i.e., how to behave... When you have given him these keys, this means of self-control, where the child will control himself, he will understand that he can't drink alcohol, not because his father forbids it... but because God can see everything, and it's a sin".

However, the demand for normativity is greater than only for the self-regulation of a person. When norms that aim to reduce the costs of interaction between people become diluted, people look for other approaches to structure their relationships. Anomie undermines a person's belief that human communities are in principle capable of forming effective and fair "game rules"; their experience does not fit with this perception.

"They [the secular government] don't comply with those laws themselves... They have prohibitions on theft and on other things. We understand it, too. But they don't comply. Anywhere. Why is theft so rampant?"; "You know, people no longer believe; they have lost their faith that anything at all can be sorted out legally".

This loss of belief leads to a desire to find a higher order normativity, which is not derived from people and which falls outside human jurisdiction. This is the type of normativity that people are trying to find in Islam, in which they believe that legal norms are established directly by God.

\footnotetext{
9 The essence of internal controls was excellently expressed by Zizek (2010, p. 107): "When I do good, I do it not to be commended by God. I do it because I can't do otherwise. If I didn't do it, I couldn't look at myself in the mirror. A moral deed is a reward in itself".
} 
"It's just, you know, laws are actually made by people. Sharia comes from God. It's from up there - a big difference. People make mistakes. Take the State Duma, for example: today, they make this law; tomorrow, they make another, but none of it really works here. That's because discord is everywhere"; "The law of Allah, sharia... There are laws made by people, and there is the Quran. It's better to establish the Quran and never change it. Once you get used to this law, you follow it until the end. People? A person makes it to the top, he satisfies his own interests, and he changes the law. That's how it works".

How is this demand satisfied?

On one hand, it is satisfied by forming a community of Muslims who share common views and values and thus reduce the uncertainty in interacting with each other in all types of areas, from labor relations to family life, etc.

"I find it easy to work with Muslims because I don't have to control them. When a person is pious, he knows that God can see everything, and he can't hide anything. I trust them. I don't have to worry about leaving money lying around"; "I sometimes talk... to Russian families of my age... Well, they have their single child, they're raising him, but I can't say that they have any... definite game rules; they're just non-existent... Islam has those rules written, and it makes it easier for people. If you can't agree about something with your wife, you just use... the knowledge from the books. And if both abide by them in the same manner, there will be no controversy, because she perceives the whole family life as deference, and he does as well. Urban populations, secularized people-they've lost it'.

In structuring relationships between people, Islamic norms play a directly applied institutional role: to resolve conflicts, people turn to the imam; sharia courts are active in many areas of Dagestan.

On the other hand, at the ideological level, it is a call to build a state fully based on God's sharia principles and thus independent from people's arbitrary will, i.e., an Islamic caliphate. This opinion is a perception of the way to ensure one of the basic values that people lose under conditions of anomie, i.e., order.

"Sharia law provides many things that can be accomplished, be it order or anything else".

At the same time, the ideal of an alternative statehood is a justification for Muslim protest against the existing state, which, in their opinion, fails to ensure justice as well as order (this opinion is explained, in particular, by the model of limited access order, associated with the weakness of the state; see North et al., 2009).

At the same time, not nearly all fundamentalists argue for armed struggle to achieve their ideals. A significant portion of them realize that laws are still implemented by people, and immoral people can distort any law, even the best one.

"In our society? And who's going to decide whether to cut hands or not?.. First, we have to build a society that would make fair decisions on cutting... This society has to be built. After the society is in place, there are the government institutions... 
There is the judge who delivers a judgment. The accused refuses. There is an institution that will make him comply with that judgment... Then the sharia laws will apply"; "Just give them sharia right here, right now, and that's it. We say, sharia is something that needs to be prepared... there are no Muslims to implement sharia".

According to moderate representatives of the movement, first, "correct" Muslims should be raised, to create the "person of the bright Islamic future" who will be fully obedient to God, and then a caliphate can be built on that basis.

It should be noted that other Islamic factions, not only Islamic fundamentalism, can and do act as tools to compensate for anomie. At the same time, fundamentalists adhere to "pure" Islam, strictly abiding by the normativity provided by the Quran and Sunnah. In the more traditional and especially "folk" forms of Islam, the basis for fighting anomie diminishes up to its complete disappearance because Islam is boiled down to the simplest of rituals and becomes closely entwined with tradition.

"We have our ancestors; I'm telling you how we used to have it... Going to the mosque on Fridays, praying, going out. A person dies - that means a procedure: wash the body, wrap it in a white cloth-all that must be done... We read the Quran... We do the burial... When the time of commemoration comes, we do the commemoration".

At the same time, traditional Islam, as a religion of ancestors and fathers, cannot satisfy the demands of youths associated with intergenerational conflict. It provides no leeway for an independent search for values and meanings without unquestioning submission to authority.

"The Imam, who stands up front: what he does, you must do. And that's it".

This authority is especially characteristic of Dagestan, where Islamic traditions are closely tied to Sufism, one of the most "vertically" structured Islamic movements, which requires unquestioning submission to the leader.

"We only had Sufism; we were all brought up in its traditions. It means we asked no questions... We had a total consensus of vision”.

Fundamentalist versions of Islam provide for a greater degree of personal freedom, but the limits of this freedom are perceived differently.

"When I say that something is wrong, I didn't come to this opinion on my own. I follow some scholars who have studied the matter and arrived at this conclusion. I was satisfied by this study, and I accepted this position... Rather than following my passions - that which I like, I follow their arguments... Sometimes, their [scholars'] discussions are written down in detail. I always try to read different opinions on any matter".

This is a moderate position. There are far more radical positions that completely deny the role of mentors. 
"Every Muslim must look for the truth... There is the Prophet, so let him be my sheik [teacher]. The others are just ordinary people”.

Other, non-religious ideologies also fail to provide an alternative capable of competing with Islamic fundamentalism. Nationalism is a good form of expressing social protest, although it is unable to satisfy the demands associated with an intergenerational conflict, which is why it can only compete with Islamic fundamentalism when some external factors consolidating the community exist, which prevent the conflict between generations from becoming fully manifested (for example, a struggle for land or for creating a separate national administrative entity). The liberal values of freedom are directly associated with anomie and are considered to be more a source of illness than of a cure.

Thus, it can be argued that the attractiveness of the Islamic fundamentalist ideology, as a compensatory mechanism during institutional collapse, arises for objective reasons and cannot be explained only by the scheming of Islamic radicals or foreign terrorist centers. This rise is associated with a number of peculiarities in this ideology, including the following:

- God is effectively included in the mechanisms of enforcement of Islamic normativity through His contract with a believer, which guarantees an afterlife in heaven and is subject to compliance with sharia law;

- based on this ideology, a transitional mechanism of social control can be formed, which does not require constant external visual supervision and, at the same time, does not rely only on internal moral norms; and

- when traditional rules and routines are destroyed, it provides at least a limited opportunity to look for solutions that correspond most with the changed situation.

\section{Conclusion: Islamic fundamentalism and the trajectory of institutional change}

The destruction of informal institutions effectively means that a "window of opportunity" has opened in a society; a chance has appeared to leave the institutional path and change the trajectory of historical development. Apparently, ideologies used as compensatory mechanisms against anomie have a substantial impact on the direction of a society's development under a greater degree of freedom. What can be expected in this regard from communities in which Islamic fundamentalism has proliferated? The answer to this question is usually unambiguous: it is a return to the past, sliding back to the Middle Ages, and an abandonment of all achievements through historical progress. It is, however, far from obvious that such a diagnosis is correct. Some researchers are not so straightforward in their understanding of this phenomenon. "Fundamentalist Islam... offers an ideology much closer... to that of the French Revolution than purveyors of common stereotypes like to admit (drawing as they do on oppositions of the Western Enlightenment to both fundamentalist religion in general and the Islamic East in particular)" (Calhoun, 1997, p. 115) ${ }^{10}$.

\footnotetext{
10 The author made this remark in the context of discussing election issues. However, throughout the paper, Islamic fundamentalism is compared to nationalism, and both ideologies are viewed as a denial of traditional relations.
} 
Here we should remember the role attributed by Max Weber to religious Protestant fundamentalism in the radical institutional transformation that led to the victory of capitalist relations. This fundamentalism never saw its goal as asserting the capitalist values of freedom, wealth and progress. "We cannot well maintain that the pursuit of worldly goods, conceived as an end in itself, was to any of them of positive ethical value... They were not the founders of societies for ethical culture nor the proponents of humanitarian projects for social reform or cultural ideals. The salvation of the soul and that alone was the centre of their life and work" (Weber, 2001, p. 48).

In what paradoxical manner could Weber have managed to prove that there was a connection between Protestant ethics and the spirit of capitalism, while neither the goals nor the values of Protestantism were directed at waking it? Weber demonstrated how new religious movements facilitated the transformation of the traditional person into the modern person, while the "cultural consequences of the Reformation were to a great extent... unforeseen and even unwished-for results of the labours of the reformers. They were often far removed from or even in contradiction to all that they themselves thought to attain" (Weber, 2001, p. 48). When that transformation had been complete, the old tools became obsolete, and new views and ideals took their place. "The people filled with the spirit of capitalism to-day tend to be indifferent, if not hostile, to the Church. The thought of the pious boredom of paradise has little attraction for their active natures; religion appears to them as a means of drawing people away from labour in this world... [A capitalist economy] no longer needs the support of any religious forces, and feels the attempts of religion to influence economic life... to be as much an unjustified interference as its regulation by the State... But these are phenomena of a time in which modern capitalism has become dominant and has become emancipated from its old supports" (Weber, 2001, pp. 32, 34).

Can we say that Islamic fundamentalism offers certain qualities that a traditional person lacks and a modern person needs? This is definitely true. Islamic fundamentalism, as well as Protestantism, requires the abandonment of traditional hierarchies and a conscious choice of one's world view, which is why Weber's thoughts regarding the role of religious fundamentalism in shaping the individualist culture are equally true in this regard. "The formation of ascetic communities and cults, with their radical denial of patriarchal chains and their interpretation of the commandment to obey God rather than people, has served as one of the central reasons for modern individualism" (Weber, 2001, p. 174).

In addition, Islamic fundamentalism requires recognition of the value of knowledge (including secular!), respect toward the law, a healthy lifestyle, and an understanding of the right to social protest. All of these qualities are features of modern urban citizenship, many traits of which are attributable to a post-modern person rather than to a modern person, i.e., to a post-modern person who comes directly from a traditional society and has not felt the disciplinary influence of industrial culture.

It is currently impossible to predict the ultimate balance of factors influencing the development of Dagestan or of the other republics of the North Caucasus in general. Apparently, the social transformation occurring there is in itself ambiguous and controversial and cannot be independent either from Russian or global processes (including those occurring in Islamic countries), which further 
complicates any forecasting. However, despite this fact (or perhaps even due to it), the experience of this region appears to carry exceptional significance for developing an institutional theory because it relies on actual field data to help understand the manner in which institutional transformation processes occur and to answer questions that were previously unanswered.

\section{References}

Bely, A. (2011). Petersburg. In A. Bely, Works (in 2 vols., vol. 1, pp. 181-514). Moscow: Alfa-Kniga (In Russian).

Brower, D. R. (1990). The Russian city between tradition and modernity, 1850-1900. Berkeley: University of California Press.

Bulgakov, S. N. (2011). Heroism and self-sacrifise (Some thoughts on religious nature of Russian intelligentsia). In Vekhy: Collection of papers on Russian intelligentsia (pp. 38-102). St. Petersburg: Azbuka-Attikus and Avalon (In Russian).

Burgess, M. (2006). Comparative federalism: Theory and practice. London: Routledge.

Calhoun, C. (1997). Nationalism. Minneapolis, MN: University of Minnesota Press.

Durkheim, E. (2005). Suicide: A study in sociology. London: Routledge.

Helmke, G., \& Levitsky, S. (2003). Informal institutions and comparative politics: A research agenda (Working paper No. 307). Kellogg Institute for International Studies, University of Notre Dame.

Inglehart, R., \& Welzel, Ch. (2005). Modernization, cultural change, and democracy. The human development sequence. Cambridge and N. Y.: Cambridge University Press.

Izgoev, A. S. (2011). On intelligent youth (Notes on its life and ideas). In Vekhy: Collection of papers on Russian intelligentsia (pp. 259-295). St. Petersburg: Azbuka-Attikus and Avalon (In Russian).

Mats, U. (1992). Ideologies as determinant of policy in modern epoch. Polis, 1, 130-142 (In Russian).

Mironov, B. N. (2000). Social history of Russia in the period of Empire (XVIII - the beginning of the XX centuries). St. Petersburg: Dmitry Bulanin Publ (In Russian).

North, D. (1990). Institutions, institutional change and economic performance. Cambridge: Cambridge University Press.

North, D. (2005). Understanding the process of economic change. Princeton and Oxford: Princeton University Press.

North, D., Wallis, J., \& Weingast, B. (2009). Violence and social orders: A conceptual framework for interpreting recorded human history. Cambridge: Cambridge University Press.

Park, R. E. (2011a). The city: Suggestions for the study of human nature in the urban environment. In R. E. Park, Selected Essays (pp. 19-56). Moscow: INION RAS (In Russian).

Park, R. E. (2011b). Sociology, community and society. In R. E. Park, Selected Essays (pp. 80-114). Moscow: INION RAS (In Russian).

Schlögel, K. (2012). Return of European cities. Otechestvenniye Zapiski, 3, 288-304 (In Russian).

Shack, W. A. (1973). Urban ethnicity and the cultural process of urbanization in Ethiopia. In Urban anthropology: Cross-cultural studies of urbanization (pp. 251-282). N. Y.: Oxford University Press.

Simmel, G. (2002). The metropolis and mental life (Ch. 1). In G. Bridge, \& S. Watson (Eds.), The Blackwell City Reader. Malden, MA: Blackwell.

Starodubrovskaya, I. V., Zubarevich, N. V., Sokolov, D. V., Intigrinova, T. P., Mironova, N. I., \& Magomedov, Kh. G. (2012). North Caucasus: Modernization challenge. Moscow: Delo (In Russian).

Weber, M. (2001). The protestant ethic and the spirit of capitalism. London. and N.Y.: Routledge. Wirth, L. (1938). Urbanism as a way of life. American Journal of Sociology, 44 (1), 1-24.

Zizek, S. (2010). On violence. Moscow: Europa (In Russian). 